\title{
Discussion on Transformation and Development of Broadcasting and Hosting Professionals in the Era of Fusion Media
}

\author{
Huixin Pei * \\ School of Art and Communication, Beijing Normal University, Zhuhai, 519087, China \\ *1044614592@qq.com
}

\begin{abstract}
With the continuous development of traditional media in China, talents in the media industry continue to emerge, and the continuous updating and upgrading of media accelerate the rapid integration of media carriers, making the birth of " Fusion Media". With the rapid update and iteration of financial media, it can be widely disseminated and applied. While the traditional media industry is impacted by financial media, it also faces new challenges and opportunities. Therefore, in the rapid development of the media industry, traditional media needs to innovate the old communication mode and content. Broadcasting and hosting professionals as the link and bridge between the masses and the media, such changes also put forward more stringent requirements on the professional ability of broadcasting and hosting professionals, and the form and content of the work has become more diversified. Hence, in order to cope with the advent of the fusion media era, it is also important to improve one's professionalism and practical skills. How can these competencies be further enhanced to meet the needs of today's media industry and the public, and what are some examples of successful transformations in the media industry? To address these questions, this paper first analyses the changes in the broadcasting industry in the context of media convergence, and then further explores the competencies that broadcasting professionals need to possess in the era of "Fusion Media". Recommendations are also provided correspondingly in the last section of this paper as well.
\end{abstract}

Keywords: Financial Media Era; Broadcasting and Hosting Professionals; Working Capability.

\section{Introduction}

In the age of fusion media, where traditional media and the self-publishing industry are constantly evolving, the masses have more diverse ways of accessing fresh information. Self-media has become more accessible to people in its fragmented and civilian form. In the face of this situation, the traditional media industry, such as newspapers and TV stations, is experiencing a decline within the audience. In response to this situation, many newspapers and TV stations have optimized and transformed their formats. The integration of traditional media and self-media is a necessary path for the development of media, and the integration between media can also promote the dissemination of information to become diversified. With the advent of the era of fusion media, the delivery channels of the media and the way the masses access information are undergoing great reform and innovation.

In the process of fusion media development and such reform and innovation, broadcasting, and hosting professionals not only play an important role as an indispensable link in the process of media delivery, but also are the backbone of promoting the development of the media industry. The requirements for broadcast hosting professionals in the era of fusion media have become more demanding, with requirements for gaining a regular audience, enhancing the appeal to the audience, and coordinating the ability to deal with unexpected situations in the work of broadcast hosting being raised, which requires broadcast hosting professionals to strengthen their overall ability to cope with the demands of the fusion era.

The internal and external transformation of broadcast professionals needs to be matched with the specific direction of media production. The development of the media industry as a whole needs to be driven by the general environment and the interests of the audience. The cultural and communicative skills of broadcast professionals are the key elements to be transformed, and the formation of a distinctive personal style and the development of their own potential is also a key 
concern to achieve the goal of promoting the rapid development of the media industry. The study of how to transform and develop the talents of broadcasting and hosting professionals in the era of fusion media will become a new idea for universities to provide education and teaching for students of broadcasting and hosting arts.

\section{The Development and Changes of the Broadcasting Profession}

\subsection{The Origins and Historical Development of the Broadcasting Profession}

The development of the broadcasting profession in China has gone through three stages, from the late 1950 s to the early 1960 s in its embryonic stage [1]. When television and radio were developed, radio and television stations and programme broadcasters were created immediately. Programme broadcasters emerged in China in the 1980s. The first broadcaster to appear as a broadcaster in New China was Xu Man in the programme "Friends on the Air" broadcast by the Central People's Radio to Taiwan.From the late 1970s to the present, the media industry in China has shown a flourishing development in general. The early nineties belonged to the formative stage. As society develops and technology advances, the media industry is growing, and this environment has created a need for a large number of broadcasting and hosting professionals. The training of broadcast hosts is of great significance to the overall quality of programmes and the development of the media industry.

\subsection{The Current State of Development of the Broadcasting Profession}

Quality of talent varies

The broadcasting and presenting arts profession are now in a booming phase. With the advent of the era of fusion media, the opportunities and challenges for broadcasting and hosting professionals have increased significantly. Because of the need for talent in the media industry, nearly 100 colleges and universities across the country have also set up broadcasting and hosting majors as a way to cultivate talent [2]. Although a large number of institutions across the country offer broadcasting and hosting arts programmes, there is no guarantee of the quality of teaching at each school. There is also a contradiction between the increasing scale of the teaching environment and the varying levels of teaching quality. Some schools simply impart knowledge without allowing students to experience the truth in social practice. And there is a shortage of teachers. Problems such as the setting of the curriculum, practical activities, the content of lectures and the layout of teaching tasks, which are key factors in determining the quality of teaching, are not perfected, and the equipment and instruments to support teaching are not well equipped. These problems inevitably lead to an inability to guarantee the quality of education. Moreover, as the art of broadcasting and hosting is a subject of art examinations, some schools lower the cultural requirements for students, while others only recruit cultural students, so that there is no unified standard for scores, which will make the cultural foundation and quality of students vary. This will further lead to an increase in pressure on the employment side of graduates in broadcasting and hosting arts, as they are restricted.

Old-fashioned teaching format and content

Firstly, many schools lack equipment for mirror classes, studios, and recording studios, or the equipment is old and does not work properly. If the hardware is not in place, then students will not be able to put theory into practice and the knowledge imparted by teachers will become empty talk [3]. Secondly, teachers are in a leading position in the education process, so their qualifications are crucial. Some teachers study literature such as communication or journalism rather than art, which leads to teachers being unhindered in imparting theoretical knowledge, but lacking experience related to broadcasting and art, they can easily read from a book and impart knowledge that is vague and not absorbed by students.

Inadequate teaching hardware and software

In terms of teaching content, in the last century broadcasters always had a high tone of voice when they read something aloud, and they did so in a single-minded manner. As time progresses and audiences change their mindset, broadcasters no longer need a high-flying style of presenting, but an 
amiable and "grounded" image [4]. However, some schools are still using the same teaching materials that have been used for decades to train broadcast broadcasters, which has resulted in students not keeping up with the times, whether they are reciting poetry or reading news scripts, they hold a "broadcast accent", which is particularly stiff and unnatural, and is not accepted by the public.

In terms of teaching format, some teachers only ask students to read aloud from the textbook, or to write their own scripts in advance and record them in front of the equipment. Although this is a good way to develop the students' ability to summaries their writing, editing, and broadcasting, it neglects the improvisational skills that are most needed in the era of fusion media [5]. This is because the new media, including online media, is all about promptness and efficiency. If you just read the script and pay attention to whether the words are correctly pronounced, but do not exercise the improvisation course, then in the face of unexpected situations and the ability to control the scene, as well as the students' psychological quality and adaptability will be lacking, unable to adapt to the development of the fusion media era.

\section{The Changing Face of the Broadcasting Profession}

\subsection{Transformation of the Content Format}

Previously, traditional variety shows were simply monotonous with the host conducting the programme flow throughout. However, in the era of fusion media, the programme does not just end with a tedious question-and-answer interaction with the guests led by the host, but also enhances the interaction with the audience, as well as the popular games and buzzwords of the day, to enhance the fun of the programme and win the audience's favorite [6]. For example, the household name guest interview game show Happy Camp has been on air for 24 years since its inception in 1997. It has always been a multi-person format hosted by five hosts, no longer stuck to the tableau, but chatting naturally, with a very lively and rich presentation and a variety of games, which has gained a large and loyal audience. This is the reason why it has stood and persisted for so many years after so many variety shows have emerged.

\subsection{Transformation of the Media Platform}

The traditional media platforms are mainly based on newspapers, radio, and television stations to deliver information. But the era of fusion media has followed, making the media industry develop rapidly on the Internet with a variety of media software and social platforms [7]. If you want to learn about news, you can browse from the software of CCTV News and Today's Headlines; if you want to listen to radio, you can listen from Himalaya FM, which has not only traditional radio stations, but also audiobooks, emotional columns, chicken soup for the soul and other columns; if you want to watch variety shows, TV series and movies, you can choose to watch them from software such as iQIYI, Tencent Video, and Mango TV. The diversity of platforms, then, makes for increased use of broadcast and hosting professionals. Not only can they host traditional programmes, but they can also appear as anchors in the live webcast platforms that have sprung up. With more jobs in the media age, there are more requirements for broadcasting professionals. From the initial need to read aloud from a script, nowadays a wide range of skills are required. Therefore, broadcasting professionals need to be well-rounded to adapt to the rapid development of the media industry.

\subsection{The Transformation of the Identity of the Broadcaster}

In different types of traditional media programmes, such as interviews, news and variety show, there are corresponding hosts. But in the era of fusion media, it is possible for the host to appear as a guest on a programme, or for example, in the programme I am a Singer, which is a programme where the participating singer acts as a host to introduce the next upcoming singer. One of Today's iconic hosts, Zhang Shaogang, has been involved in a number of network shows, such as The Trolling Conference, where he has appeared not only as a host but also as a guest "troll", and as a guest observer on Daughters in Love. Another iconic host on Today, Sa Beining has been a resident guest 
on Hello Life Season 2, a member of the cheering section on Heartwarming Offer Season 2 and a regular player on Star Detective. With his partner in Star Detective, He Jiong is also involved in a very large number of online varieties shows produced by iQIYI, Tencent Video, and Mango TV. This is a good example of the diversified requirements for broadcasting and hosting profession in the era of fusion media.

\section{Changes in the Media Industry in the Context of Media Convergence}

\subsection{Privatization of Services}

With the improvement of material life, people start to pursue spiritual affluence, so they have more requirements for the services of the media industry. So, in the context of the era of fusion media, the media industry has begun to focus on the personalization of the audience [8]. For example, NetEase Cloud Music is subdivided into several sections. In the Discover Music section, users can manually search for the music they like to listen to, and in the Friends section, they can conduct social activities and make friends with users who have the same taste in music, so that they can meet friends with songs. In the private radio FM section, NetEase Cloud Music automatically generates personalized radio FM based on the user's usual listening habits, listening style, etc. There are also daily song recommendations, which are also based on the user's favorite genre of music. This series of customized services has attracted a large number of regular users. Because the user has a good experience here, they feel a sense of belonging and that this is their own music Apps.

\subsection{Widening of Broadcast}

Today is a time when information can be transmitted quickly, and people can open various software in their mobile phones to receive any information they want to know. In the traditional media era, information was disseminated by newspapers, radio, and television stations as the medium, which were both publishers and disseminators of information. Because all this information is output unilaterally by the traditional media, it results in not receiving timely feedback from the audience groups and the news lags behind, leaving the audience groups in a passive position. In the era of integrated media, information transmission is carried out on the internet, the form of transmission has changed dramatically, and a new model has emerged in the media industry. In the transmission of information, the publisher is no longer just the traditional media, but the audience has also become the publisher, and because of the advancement of network technology, the dissemination of information is also faster and more convenient.

Sina Weibo is a social networking platform where everyone can talk, make friends, post videos, and share music, etc. It is a platform for accessing, sharing, and disseminating information. At the same time, the recipients of information are not only the audience, but also the media industry. In an era where traffic can be realized, the audience is the key customer for the media industry, which needs to produce content according to the audience's preferences and make timely adjustments through the audience's comments and feedback. For example, nowadays, the more followers a netizen has, regardless of the social platform, means the higher the economic benefits for the person himself, and fans are popularity. Behind the Netflix, there are also powerful media companies that support the operation, ranging from the persona, make-up, and clothing of this Netflix to the cooperation with brand advertisers and the content of the output message. Even celebrities must make use of the popularity of weblebrities for the purpose of their work, some co-producing short videos and some live-streaming together. The mode of disseminating information in the age of fusion media is very different from the past.

\subsection{Media Convergence}

With the rapid development of the Internet, online technology has injected fresh blood and brought strength to the media industry. The media industry also has a new ground to promote the integration of traditional media and self-media. While there are many similar and overlapping parts in the media 
industry, there are also many complementary aspects. In the era of fusion media, traditional media and self-published media complement each other and take advantage of each other's strengths and weaknesses. By complementing each other's strengths, they promote the development of the entire media industry, expanding the influence of the media and increasing the value of communication.

CCTV host Kang Hui has launched a series of Vlogs on several online social media platforms, which are different from the long-distance format of the hosts that could only be seen on TV stations in the past, this format is very daily and personal, feeling like a person around you introducing you to the content and format of his work. "The series is responsible for introducing the latest developments in China's diplomatic missions, as well as the real-life preparation, props and work of journalists. The launch of this series has attracted a large number of followers.

Many of China's broadcasters have already started to collaborate with major short-form social video software like Douyin and Kuaishou, such as CCTV, which has co-hosted the CCTV Spring Festival Gala with Douyin in 2019 and 2021. CCTV is the organizer of the Spring Festival Gala, and Jitterbug has added to its reach, allowing more young people and those away from home to watch the Gala anytime, anywhere, via mobile devices. And it also adds to the content of the Spring Festival Gala and allows for real-time interaction with the audience as well. In addition to CCTV, China's State-owned Assets Supervision and Administration Commission (SASAC) News Centre has also moved in with 25 central enterprises to collaborate with Douyin. The central enterprises that used to be so awe-inspiring are also using the power of fusion media to enter the lives of our people. This has made the positive content of the core socialist values popular in a pro-people way in the short video social software. Not only CCTV, but also local TV stations have started to cooperate with short-form social video software.

The provincial broadcaster with the largest number of followers is Sichuan TV's "Sichuan Observations". Although it appears to be a local Sichuan media account, it contains news reports about Sichuan. But in reality, it has a very diverse range of content, including not only local news, but also national news, and even foreign events. This way, if fans follow its one account, they can be informed of hot news events around the world, greatly increasing its media reach. The type of news it covers is easy to understand and the videos it publishes are relevant to our lives, and some of the criminal cases we are concerned about are also covered. It operates the account with an understanding of what the public would prefer to see, and the content is based on current affairs news and lighthearted and funny videos. The current affairs news is updated to not only meet the account's need for daily updates, but also to deliver the freshest reports to its fans in a timely manner. The light-hearted videos allow fans to laugh and relax, making a difference and successfully attracting fans with different needs.

Taking "Sichuan Observations" as a typical example, we can see that this is a new and successful attempt to integrate traditional media with new media, making full use of various media vehicles, allowing for the integration of resources and comprehensive development. Although the integration of media is not only about news, but media workers should also observe the objectivity and authenticity of the content, present it in a way that is pleasing to the people, build a solid fan base and enhance real-time interaction with fans. It is also important to move away from the high-minded, serious media image of the past and to strike a balance between seriousness and fun. This is why we should learn from the successful experience of Sichuan Watch and better explore the development of the media industry in the era of fusion media.

\section{Competencies Required of Broadcasting Professionals in the Context of Media Convergence}

\subsection{Live Streaming Capability}

In the age of fusion media, the rise of short video social software has led to the development of the entire e-commerce industry. Everyone can broadcast live with goods, not only stars and hosts, but also ordinary people are involved. Anything that is sold offline can be sold using the online platform. 
The year 2020 is the decisive year for the battle against poverty, but the sudden new crown pneumonia epidemic made the farmers' agricultural products stagnant, when the four hosts of CCTV, Ni Gemaiti, Kang Hui, Sa Beining, and Zhu Guangquan, turned into anchors with goods in order to help sell the agricultural products in Hubei. The hosts, who are household names, brought excellent agricultural products onto the CCTV stage, with the number of viewers in the live broadcast reaching more than 20 million, and sales exceeding several hundred million. This new type of live broadcast not only allows consumers to buy inexpensive products, but also helps farmers in Hubei to solve the difficulties of stagnant agricultural products. In contrast to the seriousness of the news broadcast in the past, they are humorous and witty, flirting with each other in a very personal way. Although Netflix has become a profession, it is a mix of good and bad. In the past, when people heard about Netflix and anchors, they might treat them with tinted glasses because some of them were linked to vulgarity and crowd-pleasing. Then the excellent performance of the CCTV hosts in this large-scale live broadcast set a good example for the netizens. They are broadcasting and hosting professionals, using their superb control of the scene to make the live broadcast run smoothly. They also use live streaming to help farmers and alleviate poverty, fulfilling their duties as broadcast hosting professionals and reflecting professionalism.

In the face of the new wave of live broadcast, people accept access to information more demanding timeliness [9]. This has led to more stringent requirements for broadcast professionals' ability to broadcast live as well as their other work abilities. For example, journalists, live news broadcast hosts, in the face of the live broadcast or live link, very test the broadcast host professionals on the scene and the control of the event, more test their ability to adapt to the scene. In the case of live webcasts, it is also necessary to respond to instant comments from netizens, to improve interaction, and to use simple and concise language to deliver the information that the audience wants to know in the most direct and rapid manner.

\subsection{Innovation Capacity}

Traditional media produce programmes that use broadcast broadcasters to get their message across. In the age of fusion media, broadcast broadcasters are featured in online programmes and their every move is magnified by viewers to see them. It even means that viewers will tune in on time when they see their favourite hosts hosting a programme, which shows that the personal characteristics of the broadcast hosts and their ability to think creatively have a great influence on the programme. Therefore, the relationship between the broadcasters and the programme is one of mutual achievement, as the programme gives them a stage to perform, and the broadcasters rely on their charisma and strong business skills to bring the programme high ratings. For example, Zhu Guangquan, a CCTV news broadcaster, is well known and loved on all major media platforms, especially online video social media platforms, attracting young people to learn more about current affairs of the country. This is because he has his own hosting characteristics in his programmes, adding witty and humorous segments and rhyming slurs to his news programmes as appropriate, reflecting his superb basic language skills as well as his ability to comment on current affairs. Only through continuous innovation and progress in the form of content and style of past programmes and individual broadcasters can we adapt to today's rapidly developing media industry and meet the needs of our audiences. As a broadcast host professional should use their knowledge base as well as hosting experience to have the requirement to push the boundaries of innovation, and in the process of innovation, they should also learn from their experiences and adjust themselves according to the changes in the media industry and understand the needs of the audience.

\subsection{Instant Interactive Capabilitity}

In traditional media programmes, the interaction between broadcasters and viewers was limited to telephone visits or letters, resulting in one person being on one end of the programme and the other on the other, unable to understand the audience's thoughts and opinions on the programme, or unilaterally receiving information from the audience and unable to give it back to them in a timely 
manner. Because of the lag in content and timing of the programmes, the reach is limited, and the audience is homogeneous. In the current era of fusion media, more online media is used to watch programmes, and viewers can use pop-up comments or leave comments when watching programmes. The hosts can visually see the comments and provide immediate feedback. This tests the ability of broadcast professionals to improvise when faced with questions from the audience, as well as their psychological strength when faced with negative comments. As a bridge between the programme and the audience, the host should also be able to see what the audience wants, get closer to their lives, increase interaction with the audience and expand the programme's popularity and influence [10].

\subsection{Sustainability}

In the era of fusion media, the requirements for broadcasting and hosting professionals are more diversified, as they must not only have excellent broadcasting and hosting skills, but also have a rich cultural heritage and the ability to adapt to innovation. They should be more comprehensive and diversified than just reading scripts in a proper manner in the past. They should seize the opportunity to be a media professional in the era of fusion media, and to be responsible for the professional ethics and professionalism of media professionals. For example, they should actively respond to national calls to do something meaningful. The only way to promote the sustainable development of the media industry is for broadcasting professionals to strengthen themselves and successfully transform themselves.

\section{Summary}

In short, in the face of the onslaught of self-media and the changing needs of audiences, the overall capabilities of broadcast professionals need to be enhanced accordingly. We are no longer dealing with a fixed audience, a few cameras, and crews, but with a potentially endless number of viewers on the internet. In order to ensure that the media industry's influence is not weakened in the multimedia era, what can be done is to ensure that the content broadcast is authentic, timely and correct, but also approachable and close to the lives of the audience. Although the advent of the multimedia era has brought challenges and opportunities to broadcasting professionals, the future of China's media industry is full of vitality and is unlimited. Higher education institutions should also keep up with the pace of the times and continue to cultivate and deliver new types of excellent and high-quality broadcasting and hosting professionals for the media industry. In the teaching of the art of broadcasting and hosting should also follow the trend of the times, removing the dross and taking the essence. Combined with the requirements of the media era for broadcast and hosting professionals, to update education and teaching methods, improve the cultural level of students, cultivate the spirit of innovation and practical ability. Each student is different and has their own personality. According to the characteristics of each student, we will guide the development direction suitable for them and cultivate broadcasting and hosting professionals with comprehensive ability but with their own style.

\section{References}

[1] Xing Yajing. Analysis of the development of television broadcasting business. Literature and art life. Wenhai Yiyuan. 2015 No. 4.

[2] Zhao Fangbo. An introduction to the future development of broadcasting and hosting. Heilongjiang Science and Technology Information. 2013.17.

[3] Fang Yanfan. Innovation and thinking of broadcasting and hosting teaching. Group Text World. 2012. 5.

[4] Li Yu. Cultivation and development strategies of broadcasting host talents. News Outpost. 2018, Issue 2.

[5] Zhang Jiaxin. Research on the development and countermeasures of college broadcasting and hosting art education under media integration. Ji Fu Times, 2015.

[6] He Peishan. Discussion on the development of broadcasting and hosting in the new media environment. Literature and art life. Lower Journal. 2019-7. 
[7] Zhang Xiaoyan. Where to go for announcer hosts in the context of new media. Journalism Research Guide, 2019 (13).

[8] Zhao Xin. Talking about the transformation and upgrading of radio and television broadcast hosts in the era of full media. Western Radio and Television, 2016(22):173.

[9] Luo Li. Abilities that broadcast presenters should have in the context of media integration. Communication Power Research.2019.140.

[10] Li Bing. Exploration of the competencies that television broadcast hosts should have in the context of media convergence. China TV, 2016 (11): 106-108. 